\title{
Depression and Internet use in a Sample of Malaysian Undergraduate Students
}

\author{
${ }^{*} \mathrm{Lu}$ Xi, Yeo Kee Jiar \\ Universiti Teknologi Malaysia, Malaysia \\ *luxi0218@gmail.com
}

\begin{abstract}
This study used a set of questionnaire to investigate the Internet use and depression level in a sample of Malaysian undergraduate students, which identified 12 cases as pathological Internet use (PIU) in a total sample of 90 students using Beard and Wolf's (2001) criterion. Students with PIU spent significantly longer time on Internet and experienced extremely higher level of depression $(\mathrm{M}=42.83$, $\mathrm{SD}=11.86$ ) than their non-PIU counterparts ( $M=26.26, \mathrm{SD}=14.79)$, which is in the severe level. The gender difference on depression was also detected in this study but not for time spent online. Lastly, this study found that students with PIU would like to spent more time on SNS, browsing with no specific purpose, and online media viewing, while students with increasing level of depression would accelerate the time spent online, especially on SNS, browsing with no specific purpose, and instant messaging. The same Internet application (SNS and browsing with no specific purpose) chose by students with PIU and high level of depression implied that there may be close association on developing depression and PIU related to usage of SNS and browsing with no specific purpose.
\end{abstract}

\section{Keywords: PIU, Depression, Malaysian undergraduate students}

\section{Introduction}

Internet become a critical part of modern life, which brings huge change and convince; people spend more and more time online, ranged from 19 to 68 hours per week (Li, Wang, \& Wang, 2009; Hardie \& Tee, 2007). Beside its benefits on various aspects, the darker side of Internet could not be ignored. Griffiths $(1998$, p. 73$)$ indicated that "excessive use of the Internet may not be problematic in most cases but the limited case study evidence suggests that for some individuals, excessive Internet use is a real addiction and of genuine concern". The term to describe those people is not consistent, which include "Pathological Internet use, Internet Addiction Disorder, Internet addiction, Internet addicts, Problematic Internet use, computer-medicated communication addicts, computer junkies, maladaptive patterns of Internet use, etc" (Caplan, 2002; Davis, 2001; Beard \& Wolf, 2001; Chou, Chou and Tyan, 1999; Goldberg, 1996; Young, 1996). This research will take the term "Pathological Internet use", which refers to the excessive use of Internet and significantly influences one's normal life including psychological, family, social problems (Beard \& Wolf, 2001; Davis, 2001). Davis (2001) proposed depression as the distal necessary cause of pathological Internet use (PIU). Most subsequent researches confirmed that PIU was positively associated with depression (Morrison \& Gore; 2010; Yang \& Tung; 2007; Kim, Ryub, Chon, Yeunb, Choic, Seod \& Nam, 2006; Whang, Lee \& Chang, 2003). A big scale investigation among high students population found that Internet addiction was related to symptoms of ADHD and depressive disorders. This study further explained that high school students with high depression mood may fascinated on virtual life online to adjust their emotional condition as they perceived Internet harmless and more available than illegal substances. However, it is possible that they may accelerate time online and progress to addiction, if the depression was not well treated (Yen, Ko, Yen, Wu, \& Yang, 2007).

However, a study in Chinese Tai Wan found that depressive tendency was negatively associated with PIU. Students with depression tendency would escape from any relationship and communication including online social interaction, which decrease the possibility to become PIU (Harn, Wu, Chen \& Chang, 2007). The different Internet application and depression was also studied which found that depression symptoms was associated with chatting online and e-mailing, while chatting online was related to prolonged stress, and surfing the Internet was associated with an increased risk of developing sleep disturbances in the form of repeated awakenings (Thomee, Eklo, Gustafsson, Nilsson \& Hagberg, 2007). In Malaysia, Ling, Ramadass Altaher and Arjuman (2011) pointed that younger generations were at-risk to the addictive behavior. Individual in the age group of 18-25 is more susceptible to get PIU, especially the students in universities or colleges. An investigation on a sample of medical student reported that those student spent average of 13.31 hours online per week and started using computers at the age of 14 
(Guan,Isa, Hashim, Pillai \& Singh, 2012). But research to study the relationship of depression and PIU is limited sparse in Malaysia context. As the inconsistent findings in foreign context, the similar research should be encouraged and necessary to carry out in Malaysian context, which could not only add more academic evidence in this field, but also enrich the academic researches of Malaysia. This study took a group of undergraduate students in Malaysia to examine their Internet use status, as well as the relationship of depression and PIU. Following are the objectives of the study:

- To validate the psychometric properties of DASS-D in Malaysian context.

- To identify the cases of students with PIU in a sample of Malaysian undergraduate students.

- To identify the interactive and main effect of gender and group on time spent online per day, DASS-D.

- To identify the relationship of DASS-D and time spent on different Internet application

\section{Methodology}

Participants: A total of 90 undergraduate students from Faculty of Education in Univerisiti Teknologi Malaysia completed the pencil paper questionnaire. Majority of participants are Malay (78.9\%), followed by Chinese (15.6) and others (5.6\%). The age range was 19-29 years old.

\section{Measure}

Internet use Questionnaire. The Internet use questionnaire was designed by the researcher for this study to collect the basic information of Internet use, such as time spent online per day, time spent on different Internet applications.

Internet addiction Diagnostic Questionnaire (DQ): Young (1998) developed an eight-item Internet addiction Diagnostic Questionnaire (DQ) based on the diagnostic criterion of Pathological Gambling. Individuals who answer "yes" to five or more of the eight items can be classified as addicted Internet users (Dependents), while others could be classified as normal Internet users (Non-Dependents) (Young, 1998). Later, Beard and Wolf (2001) suggested a stricter borderline, which considered that individual who answered "yes" on all of the first five questions and at least any one of the remaining three questions were deemed as suffering by PIU. This study will take the stricter borderline to separate this sample of students into PIU and non-PIU groups. It was translated into various language, such as Greek (Siomos, Dafouli, Braimiotis, Mouzas \& Angelopoulos, 2008; Frangos, Frangos \& Kiohos, 2010), Norwegian (Johansson \& Götestam, 2004), Chinese (Cao, Su, Liu \& Gao, 2007). Previous research found that the Greek version of YDQ had satisfactory reliability on split-half and Cronbach's alpha test $(>0.70)$, and validity on dimensionality test using principal component analysis (PCA) (Siomos, Dafouli, Braimiotis, Mouzas \& Angelopoulos, 2008; Frangos, Frangos \& Kiohos, 2010), good diagnostic accuracy with sensitivity analysis as well (Frangos, Frangos \& Kiohos, 2010). Johansson and Götestam (2004) found similar result with the Greek version, which showed a good reliability and consistency in split-half test (0.729) and Cronbach's alpha (0.713), unidimentionality in principal component analysis (PCA). The Chinese version of YDQ was reported with a good reliability on split-half reliability and Cronbach's alpha, which were 0.719 and 0.722 respectively (Cao, Su, Liu \& Gao, 2007).

Depression subscale of DASS: DASS- Depression Anxiety Stress Scale is a set of self- report scales designed to measure depression (dysphoria, hopelessness, devaluation of life, self depreciation, lack of interest, anhedonia and inertia), anxiety (autonomic arousal, skeletal muscle effects, situational anxiety and subjective experience of the anxious affect) and stress (difficulty relaxing, nervous arousal, being easily upset, agitation, irritability and impatience) (Lovibond \& Lovibond, 1995). Lovibond and Lovibond (1995) reported satisfactory level of reliability using Cronbach's alpha for the depression, anxiety and stress scales (0.91, 0.84 and 0.90 , respectively) among a large non-clinical sample $(\mathrm{N}=2,914)$. Another study also found high internal consistency tested by Cronbach's alpha among large clinical samples $(0.96$, 0.89 and 0.93 for Depression, Anxiety, and Stress, respectively). Test-retest reliability was ranged from 0.71 to 0.81 . Construct validity was confirmed by factor analysis, as well as convergent and discriminant validity of the scales (Brown, Chorpita, Korotitsch \& Barlow, 1997). The psychometric properties of 42 items and 21 items version of DASS was examined in nonclinical volunteers and patients, found that DASS distinguishes well between features of depression, physical arousal, and psychological tension and agitation and extends these observations to the DASS-21. The internal consistency and concurrent validity of the DASS and DASS-21 were in the acceptable to excellent ranges (Antony, Bieling, Cox, Enns \& Swinson, 1998). 
Henry and Crawford (2005) reported the reliability of depression, anxiety and stress subscale of DASS-21 with value of coefficient $0.88,0.82,0.90$ respectively among 1794 general adults in UK. The study also indicated that the DASS-21 did evidence good convergent and discriminate validity compared with other validated measures of depression and anxiety. The DASS-21 subscales can validly be used to measure the dimensions of depression, anxiety, and stress. Lu (2011) translated the DASS-21 to Malay and adapted the Chinese version, which found that the internal consistency of Cronbach's alpha on Depression subscale of DASS-21 (appeared with three language including English, Malay, and Chinese) was 0.865. This study adapted the Malay and Chinese version of DASS-D from Lu's (2011) study and further modified its original four-point scale into six-point semantic differential scale with 0 for never and 5 for always. This adapted version of DASS-D used the original scoring method, which is to multiply the summed scores of seven items by 2 . Then the score range is $0-70$. High score indicate high level of depression. The score above 35 is considered as severe which transferred from the original severity rating guideline $(21$ for severe).

\section{Result}

\section{Rasch Model Analysis on Items using Winsteps for DASS-D}

Category Structure of Rating Scale on DASS-D: Table 1 showed that result of category structure for DASS-D, which is to examine the rating scale with six categories. The value of observed average measure increases with the category value $(-4.08,-2.49,-.75, .33,1.9$ and 2.45 for categories $1,2,3,4$ and 5 respectively) and is close to sample expect value. The value of structure calibration also increases with the category value, which indicated that there was no disordered category. The value of INFIT and OUTFIT is close to 1 on categories $1,2,3$, and 4 (from 0.79 to 1.10 ). Only category 5 reported a higher value of INFIT and OUTFI (1.61 and 1.52), which is less than 2.0 and acceptable for practical purposes.

Table 1: Category Structure

\begin{tabular}{ccccccccll}
\hline \multicolumn{2}{c}{$\begin{array}{c}\text { Category } \\
\text { Label Score Count \% }\end{array}$} & \multicolumn{2}{l}{$\begin{array}{l}\text { Obsverved Sample } \\
\text { Avrge Expect }\end{array}$} & \multicolumn{2}{l}{$\begin{array}{l}\text { INFIT OUTFIT } \\
\text { MNSQ MNSQ }\end{array}$} & $\begin{array}{l}\text { Structure } \\
\text { Calibratn }\end{array}$ & $\begin{array}{l}\text { Category } \\
\text { Measure }\end{array}$ \\
\hline 0 & 0 & 88 & 14 & -4.08 & -4.07 & 1.01 & .99 & NONE & $(-5.47)$ \\
1 & 1 & 155 & 25 & -2.49 & -2.41 & .79 & .81 & -4.33 & -3.02 \\
2 & 2 & 152 & 24 & -.75 & -.88 & .96 & .97 & -1.59 & -.95 \\
3 & 3 & 154 & 24 & .33 & .36 & 1.10 & 1.10 & -.26 & .88 \\
4 & 4 & 63 & 10 & 1.90 & 1.80 & .96 & .95 & 1.94 & 3.12 \\
5 & 5 & 18 & 3 & 2.45 & 3.09 & 1.61 & 1.52 & 4.24 & $(5.41)$ \\
\hline
\end{tabular}

Category probability curve is an observable and easy method to examine the function of rating scales. As shown in Fig 1, all the category has a distinct peak which implied a good performance of this six categories.

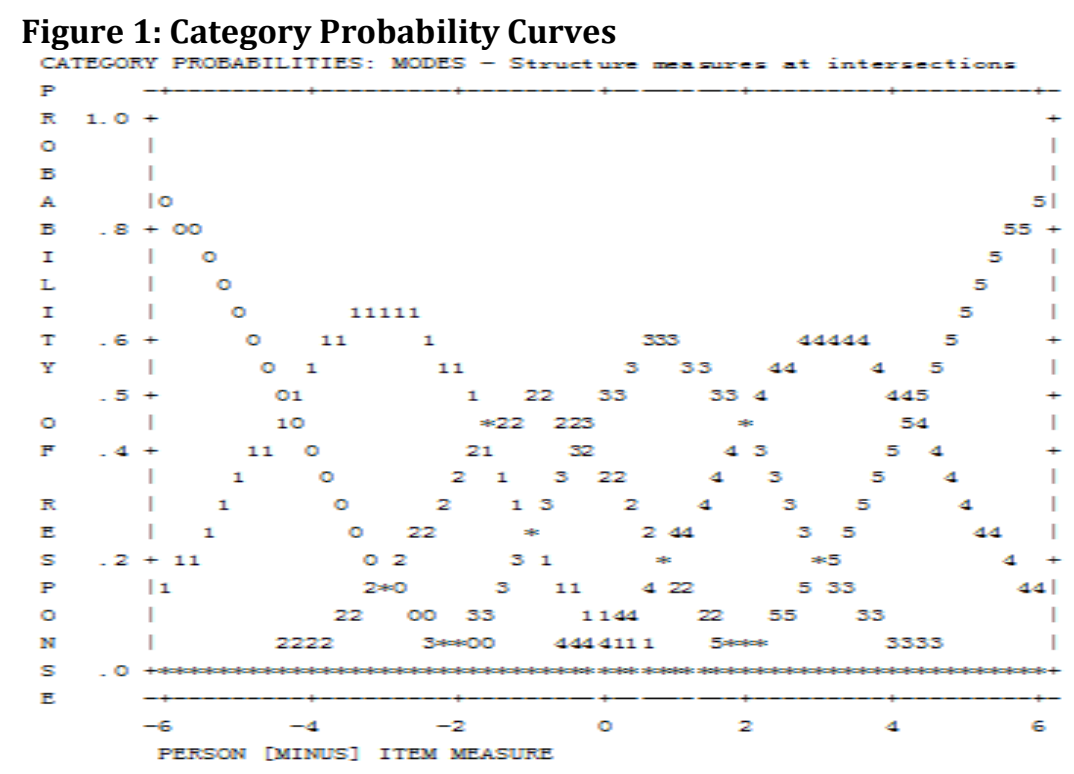


Dimensionality Test for DASS-D: The result of Rasch principal component analysis (PCA) in table 2 indicated that the raw variance in observations of DASS-D was $68.4 \%$ with 15.2 Eigenvalue units. The unexplained variance in the first contrast was $6.9 \%$ with 1.5 Eigenvalue units, which lower than 2 and meet the unidimensionality of Rasch model assumption.

Table 2: Standardized Residual Variance of DASS-D (in Eigenvalue units)

\begin{tabular}{lcccc}
\hline & & -- Empirical -- & Modeled \\
\hline Total raw variance in observations & $=$ & 22.2 & $100.0 \%$ & $100.0 \%$ \\
Raw variance explained by measures & 15.2 & $68.4 \%$ & $68.1 \%$ \\
Raw variance explained by persons $=$ & 11.3 & $51.2 \%$ & $50.9 \%$ \\
Raw Variance explained by items $=$ & 3.8 & $17.2 \%$ & $17.1 \%$ \\
Raw unexplained variance (total) $=$ & 7.0 & $31.6 \%$ & $100.0 \%$ & $31.9 \%$ \\
Unexplned variance in 1st contrast $=$ & 1.5 & $6.9 \%$ & $21.9 \%$ & \\
Unexplned variance in 2nd contrast $=$ & 1.5 & $6.6 \%$ & $20.9 \%$ & \\
Unexplned variance in 3rd contrast $=$ & 1.2 & $5.6 \%$ & $17.9 \%$ & \\
Unexplned variance in 4th contrast $=$ & 1.0 & $4.5 \%$ & $14.3 \%$ & \\
Unexplned variance in 5th contrast $=$ & .9 & $4.2 \%$ & $13.4 \%$ & \\
\hline
\end{tabular}

Table 3 is the Rasch analysis result of item fit statistics in misfit order, which showed that all the pointmeasure correlation (CORR.) are positive and high, ranged from 0.79 to 0.89 , all are close to the expected correlation (EXP.). It implied that all the items are aligned with the abilities of person. The values of INFIT and OUTFIT MNSQ for all the items are in the well fit range from 0.6 to 1.4, except items 2 (1.43 and 1.49 for INFIT and OUTFIT respect).

Table 3: Item Fit Statistics of DASS-D in Misfit Order

\begin{tabular}{|c|c|c|c|c|c|c|c|c|c|c|c|}
\hline \multirow{2}{*}{$\begin{array}{l}\text { Entry } \\
\text { No. }\end{array}$} & Total & \multirow[b]{2}{*}{ Count } & \multirow[b]{2}{*}{ Measure } & \multirow{2}{*}{$\begin{array}{c}\text { Model } \\
\text { S.E. }\end{array}$} & \multicolumn{2}{|c|}{ INFIT } & \multicolumn{2}{|c|}{ OUTFIT } & \multirow{2}{*}{$\begin{array}{l}\text { PT- } \\
\text { Measure } \\
\text { CORR. } \\
\text { EXP. }\end{array}$} & \multirow{2}{*}{$\begin{array}{c}\text { EXACT } \\
\text { MATCH } \\
\text { OBS\% } \\
\text { EXP\% } \\
\end{array}$} & \multirow[b]{2}{*}{ Item } \\
\hline & Score & & & & $\begin{array}{l}\text { MNSQ } \\
\text { ZSTD } \\
\end{array}$ & & $\begin{array}{l}\text { MNSQ } \\
\text { ZSTD }\end{array}$ & & & & \\
\hline 2 & 204 & 90 & -.59 & .16 & 1.43 & 2.5 & 1.49 & 2.9 & A.79 .85 & 46.451 .1 & $\mathrm{~d} 2$ \\
\hline 7 & 143 & 90 & .96 & .16 & 1.38 & 2.3 & 1.38 & 2.2 & В.78 .82 & 45.254 .7 & $\mathrm{~d} 7$ \\
\hline 6 & 187 & 90 & -.17 & .16 & 1.14 & .9 & 1.12 & .8 & C .83 .84 & 52.453 .5 & d6 \\
\hline 3 & 192 & 90 & -.29 & .16 & .89 & -.7 & .90 & -.6 & D .86 .85 & 57.152 .6 & d3 \\
\hline 1 & 183 & 90 & -.07 & .16 & .85 & -1.0 & .84 & -1.0 & с .86 .84 & 63.153 .4 & $\mathrm{~d} 1$ \\
\hline 5 & 177 & 90 & .08 & .16 & .66 & -2.5 & .63 & -2.8 & b .88 .84 & 64.354 .0 & $\mathrm{~d} 5$ \\
\hline 4 & 177 & 90 & .08 & .16 & .58 & -3.2 & .57 & -3.4 & a $.89 \quad .84$ & 70.254 .0 & $\mathrm{~d} 4$ \\
\hline Mean & 180.4 & 90.0 & .00 & .16 & .99 & -.2 & .99 & -.3 & & 57.053 .3 & \\
\hline S.D. & 17.6 & .0 & .45 & .00 & .31 & 2.1 & .33 & 2.2 & & $8.8 \quad 1.1$ & \\
\hline
\end{tabular}

The summary of person and item on DASS-D reported moderate to high level of person and item separation (3.07 and 2.44 respectively). Combining the test of result on category function, dimensionality and item fit, DASS-D was deemed as an instrument with good reliability and validity in Malaysian undergraduate students.

Depression and Internet use among Malaysian undergraduate students: There were 12 students who met Beard and Wolf's (2001) criterion classified as PIU, the others were considered as non-PIU. The descriptive data in Table 4 showed that students in PIU reported higher mean value of time spent online and DASS-D than those in non-PIU. The inferential test to compare group difference using MANOVA, first test the interactive effect of group and gender, which did not find the significant interactive effect of group and gender on time spent online and DASS-D (MS=7.4, F=0.940, $\mathrm{P}=0.335$; $\mathrm{MS}=414.88, \mathrm{~F}=2.40$, $\mathrm{P}=0.125$, respectively). Then MANOVA test was conducted again to examine the main effect of group and gender without interactive effect setting. The result shown in Table 5 indicated that there was significant main effect of group on time spent online per day and DASS-D. In other word, students in PIU reported significant more time online, higher score of DASS-D, and more years of experience with Internet, compared with students in non-PIU group. The significant main effect of gender was only found on DASS- 
D, which meant that males reported significant higher score on DASS-D than females, and there was no significant difference of time spent online per day between males and females.

Table 4: Mean values of time spent online, DASS-D for the PIU and non-PIU groups

\begin{tabular}{lllllll}
\hline & group & gender & Mean & SD & N \\
\hline time spent online per day & non- & male & 5.97 & 3.15 & 33 \\
& PIU & female & 4.63 & 2.69 & 43 \\
& & total & 5.21 & 2.95 & 76 \\
& \multirow{2}{*}{ PIU } & male & 7.43 & 2.15 & 7 & 5 \\
DASS-D & & female & 7.80 & 1.79 & 12 & 33 \\
& & total & 7.58 & 1.93 & 13.94 & 43 \\
& non- & male & 33.94 & 12.67 & 76 \\
& PIU & female & 20.37 & 14.79 & 7 \\
& & total & 26.26 & 4.07 & 7 \\
& PIU & male & 43.14 & 16.99 & 5 \\
& & female & 42.40 & 42.83 & 11.86 & 12 \\
\hline
\end{tabular}

Table 5: Comparison of time spent online and DASS-D

\begin{tabular}{lllll}
\hline & & MS & F & P \\
\hline group & time spent online per day & 50.74 & 6.52 & 0.01 \\
& DASS-D & 2361.45 & 12.23 & 0.00 \\
gender & time spent online per day & 25.97 & 3.33 & 0.07 \\
& DASS-D & 2797.010 & 15.67 & 0.00 \\
\hline
\end{tabular}

Depression and Different Internet Application: As shown in table 6, there were significantly positive relationship between the score of DASS-D and time spent on eight Internet application including MMORPG, SNS, search/googling, simple online games, online shopping, browsing with no specific purpose, online media viewing and instant messaging. The correlation was in moderate level between DASS-D and time spent on SNS, browsing with no specific purpose, and instant messaging $(r>0.40)$.

Table 6: Correlation of DASS-D and time spent on Different Internet application

\begin{tabular}{llll}
\hline & $\mathbf{R}$ & $\mathbf{P}$ & $\mathbf{N}$ \\
\hline MMORPG & 0.215 & 0.04 & 90 \\
SNS & 0.412 & 0.00 & 90 \\
email & 0.120 & 0.26 & 90 \\
search /googling & 0.345 & 0.00 & 90 \\
simple online games & 0.212 & 0.04 & 90 \\
online shopping & 0.241 & 0.02 & 90 \\
browsing with no specific purpose & 0.451 & 0.00 & 90 \\
online media viewing & 0.358 & 0.00 & 90 \\
instant messaging & 0.411 & 0.00 & 90 \\
others & 0.070 & 0.49 & 90 \\
\hline
\end{tabular}

To further control the effect of PIU, MANOVA test was conducted which included group (PIU and non-PIU) as fixed factor, DASS-D as covariate found a significant main effect for DASS-D (Wilks' $\lambda=0.75, F=2.58, P$ $=0.009$ ), but not for group (Wilks' $\lambda=0.82, F=1.68, P=0.098$ ). Given the significance of the overall test, the univariate main effect were examined, which found that the significant main effect for DASS-D were obtained for time spent on MMORPG, SNS, search/googling, simple online games, online shopping, browsing with no specific purpose, online media viewing and instant messaging (Table 7). This result 
support the correlation result, which showed significant positive relationship between DASS-D and time spent on MMORPG, SNS, search/googling, simple online games, online shopping, browsing with no specific purpose, online media viewing and instant messaging. Although the significant main effect for group was not found in overall test, the univariate main effect test found that the significant main effect for DASS-D were only obtained for time spent on three Internet application including SNS, browsing with no specific purpose, online media viewing.

Table 7: DASS-D and time spent on different Internet application

\begin{tabular}{lllll}
\hline & $\begin{array}{l}\text { Time spent on different Internet } \\
\text { application }\end{array}$ & MF & F & Sig. \\
\hline group & MMORPG & 1.41 & 0.50 & 0.48 \\
& SNS & 53.09 & 7.72 & 0.01 \\
email & 0.50 & 0.58 & 0.45 \\
& search /googling & 9.50 & 1.25 & 0.27 \\
simple online games & 0.39 & 0.24 & 0.63 \\
online shopping & 1.13 & 0.57 & 0.45 \\
browsing with no specific purpose & 28.78 & 5.27 & 0.02 \\
online media viewing & 27.18 & 4.66 & 0.03 \\
instant messaging & 0.38 & 0.14 & 0.71 \\
others & 0.35 & 0.16 & 0.69 \\
MMSS-D & 13.31 & 4.75 & 0.03 \\
& SNS & 65.11 & 9.46 & 0.00 \\
email & 1.55 & 1.79 & 0.18 \\
search /googling & 59.82 & 7.86 & 0.01 \\
simple online games & 7.00 & 4.26 & 0.04 \\
online shopping & 7.05 & 3.54 & 0.06 \\
browsing with no specific purpose & 73.78 & 13.50 & 0.00 \\
online media viewing & 40.06 & 6.87 & 0.01 \\
instant messaging & 38.73 & 14.23 & 0.00 \\
others & 0.55 & 0.25 & 0.62 \\
\hline
\end{tabular}

Discussion: This study identified 12 cases as pathological Internet use (PIU) in a total sample of 90 Malaysian undergraduate students using Beard and Wolf's (2001) criterion, which is much lower than the recent study on a sample of 162 university students with $43 \%$ classified as PIU (Guan,Isa, Hashim, Pillai \& Singh, 2012). This is the only study using the same instrument of Young's DQ and conducting on university students in Malaysia context, but applied Young's criterion which is more easily detected as PIU. The huge distance on the proportion of cases identified in Guan's (2012) study and this research may be due to the different borderline applied. But the limited sample source restricted in Education Faculty and its small size may be another influence of differences. Besides the inconsistent instrument for PIU and lack of national scale study, the previous studies in Malaysian reported a considerable high proportion of case identified as PIU (Guan et al., 2012; Ling et al., 2011; Rahmat, 2004) ranged from 29\% to $48 \%$. This study backed up the evidence of past findings that pathological Internet use among university students become general with the population of Internet use. Another finding of this study indicated that students with PIU spent significantly longer time on Internet and experienced extremely higher level of depression $(M=42.83, S D=11.86)$ than their non-PIU counterparts $(M=26.26, S D=14.79)$, which is in the severe level. This finding was consistent with most previous studies (Morrison \& Gore; 2010; Yang \& Tung; 2007; Kim, Ryub, Chon, Yeunb, Choic, Seod \& Nam, 2006; Whang, Lee \& Chang, 2003). Although a study in Chinese Tai Wan found that individual with severe depression level would escape from any relationship and communication including online social interaction, which decreases the possibility to become PIU (Harn, Wu, Chen \& Chang, 2007). Contradictorily, this study found that depression level was significantly 
positively related to time spent online, especially on two social function Internet applications (SNS and instant messaging) and browsing with no specific purpose.

The gender difference on depression was also detected in this study by including the effect of group difference, which reported that male students experienced significantly higher level of depression than female students. But regarding to time spent online, there was no significant difference between male and female students. Gender difference was well studied by previous research which was not consistent, some reported male spent more time online (Durkee et al., 2012; Li \& Chung, 2006), and some did not found (Lu, Watanabe, Liu, Uji, Shono, \& Kitamura, 2011; Li, Wang, \& Wang, 2009; Azim, Zam \& Rahman, 2009; Kim, Ryub, Chon, Yeunb, Choic, Seod, Nam, 2006; Rahmat, 2004). Although this study found male students spent more time online than female students in non-PIU group and reverse situation in PIU group which female students spent more time online, the significantly statistical difference was not found between male and female. It may be due to the small samples in non-PIU groups.

Lastly, this study found that students with PIU would like to spent more time on SNS, browsing with no specific purpose, and online media viewing, which support evidence of Kim, LaRose and Peng's (2009) study that deemed SNS and instant messaging as favorite online activity. Differently, Gencer and Koc (2012) found that individual with PIU spent more time on BBSs, the WWW, e-mail, and games. The different findings of time spent on Internet application by previous studies and this research may be related to the various sample and different categorizing of Internet application. This study further pointed that students with increasing level of depression would accelerate the time spent online, especially on SNS, browsing with no specific purpose, and instant messaging. Although the cause and effect of depression and PIU was not examined in this study, the same Internet application (SNS and browsing with no specific purpose) chose by students with PIU and high level of depression implied that there may be close association on developing depression and PIU based on Internet us of SNS and browsing with no specific purpose.

\section{Conclusion and Future Study}

This study identified 12 cases as pathological Internet use (PIU) in a total sample of 90 students, which called for the attention from the universities and parents. Students with PIU spent significantly longer time on Internet and experienced extremely higher level of depression than their non-PIU counterparts. The same Internet application (SNS and browsing with no specific purpose) chose by students with PIU and high level of depression suggested future study on the relationship between depressions and PIU related to usage of SNS and browsing with no specific purpose.

\section{References}

Antony, M. M., Bieling, P. J., Cox, B. J., Enns, M. W. \& Swinson, R. P. (1998). Psychometric properties of the 42-item and 21-item versions of the Depression Anxiety Stress Scales in clinical groups and a community sample. Psychological Assessment, 10, 176-181.

Azim, D. H. B. F., Zam, N. A. B. M. \& Rahman, W. R. A. (2009). Internet Addiction between Malaysian Male and Female undergraduate Human Sciences Students of The International Islamic University Malaysia. The 6 $6^{\text {th }}$ International Postgraduate Research Colloquium, p58-74. Srinakharinwirot University in Bangkok, Thailand.

Beard, K. W. \& Wolf, E. M. (2001). Modification in the proposed diagnostic criteria for Internet addiction. Cyberpsychology and Behavior, 4, 377-383.

Brown, T. A., Chorpita, B. F. \& Korotitsch, W. \& Barlow, D. H. (1997). Psychometric Properties of the Depression Anxiety Stress Scales (DASS) in Clinical Samples. Behaviour Research and Therapy, 35(1), 79-89.

Cao, F. L., Su, L. Y., Liu, T. Q. \& Gao, X. P. (2007). The relationship between impulsivity and Internet addiction in a sample of Chinese adolescents. European Psychiatry, 22, 466-471. doi:10.1016/j.eurpsy.2007.05.004

Caplan, S. E. (2002). Problematic Internet use and psychosocial well-being: development of a theorybased cognitive-behavioral measurement instrument. Computers in Human Behavior, 18, 553575.

Chang, M. K. \& Man Law, S. P. (2008). Factor structure for Young's Internet Addiction Test: A confirmatory study. Computers in Human Behavior, 24, 2597-2619. 
Chou, C., Chou, J. \& Tyan, N. N. (1999). An exploratory study of Internet addiction, usage and communication pleasure-The Taiwan's case. Int. J. Educ. Telecommun, 5(1), 47-64.

Davis, R. A. (2001). A cognitive-behavioral model of pathological Internet use. Computers in Human Behavior, 17, 187-195.

Durkee, T., Kaess, M., Carli, V., Parzer, P., Wasserman, C., Floderus, B., Apter, A., Balazs, J., Barzilay, S., Bobes, J., Brunner, R., Corcoran, P., Cosman, D., Cotter, P., Despalins, R., Graber, N., Guillemin, F., Haring, C., Kahn, J. P., Mandelli, L., Marusic, D., Mészáros, G., Musa, G. J., Postuvan, V., Resch, F., Saiz, P.A., Sisask, M., Varnik, A., Sarchiapone, M., Hoven, C. W. \& Wasserman, D. (2012). Prevalence of pathological internet use among adolescents in Europe: demographic and social factors. Addiction, 107(12), 2210-2222. doi:10.1111/j.1360-0443.2012.03946.x

Frangos, C. C., Frangos, C. C. \& Kiohos, A. P. (2010). Internet addiction among Greek university students: Demographic associations with the phenomenon, using the Greek version of Young's internet addiction test. International Journal of Economic Sciences and Applied Research, 3(1), 49-74.

Gencer, S. L. \& Koc, M. (2012). Internet Abuse among Teenagers and Its Relations to Internet Usage Patterns and Demographics. Educational Technology \& Society, 15(2), 25-36.

Goldberg, I. (1996). Interne addiction. Electronic message posted to Research Discussion List. Research @ PsyCom.net World Wide Wbe, http://www. cmhc. com/mlists/research/ and http://wwwusr.rider.edu/ suler/psycyber/supportgp.html

Griffiths, M. D. (1998). Internet addiction: Does it really exist? In Gackenbach, J. (ed.), Psychology and the Internet: Intrapersonal, Interpersonal, and Transpersonal Implications, Academic Press, New York.

Guan, N. C. Isa, S. M. Hashim, A. H. Pillai, S. K. \& Singh, M. K. H. (2012). Validity of the Malay Version of the Internet Addiction Test: A Study on a Group of Medical Students in Malaysia. Asia-Pacific Journal of Public Health, 10(1).

Hardie, E. \& Tee, M. Y. (2007). Excessive Internet use: The role of personality, loneliness and social support networks in Internet addiction. Australian Journal of Emerging Technologies and Society, $5(1), 34-47$.

Henry, J. D. \& Crawford, J. R. (2005). The Short-form Version of the Depression Anxiety Stress Scales (DASS-21): construct validity and normative data in a large non-clinical sample. The British Journal Of Clinical Psychology, 44(2), 227-39. The British Psychological Society.

Johansson, A. \& Götestam, K. G. (2004). Internet addiction: characteristics of a questionnaire and prevalence in Norwegian youth (12-18 years). Scandinavian Journal of Psychology, 45, 223-229.

Kim, J. LaRose, R. \& Peng, W. (2009). Loneliness as the Cause and the Effect of Problematic Internet Use: The Relationship between Internet Use and Psychological Well-being. Cyber Psychology \& Behavior, 12(4), 451-455. DOI: 10.1089=cpb.2008.0327

Kim, K., Ryub, E. J., Chon, M. Y., Yeunb, E. J., Choic, S. Y., Seod, J. S. \& Nam B. Y. (2006). Internet addiction in Korean adolescents and its relation to depression and suicidal ideation: A questionnaire survey. International Journal of Nursing Studies, 43, 185-192.

Lai, C. M., Mak, K. K., Watanabe, H., Ang, R. P., Pang, J. S. \& Ho, R. C. M. (2013) Psychometric Properties of the Internet Addiction Test in Chinese Adolescents. J.Pediatr. Psychol., 3, 1-14. doi:10.1093/jpepsy/jst022

Li, H. H., Wang, J. Q. \& Wang, L. (2009). A Survey on the Generalized Problematic Internet Use in Chinese College Students and its Relations to Stressful Life Events and Coping Style. Int J Ment Health Addiction, 7(2), 333-346. DOI 10.1007/s11469-008-9162-4.

Li, S. M. \& Chung, T. M. (2006). Internet function and Internet addictive behavior. Computers in Human Behavior, 22, 1067-1071.

Ling, C. S., Ramadass S., Altaher, A. \& Arjuman, N. C. (2011). Malaysian Internet Surfing Addiction (MISA): Factors Affecting the Internet Use and Its Consequences. 2011 International Conference on Computer Applications and Industrial Electronics (ICCAIE 2011).

Lovibond, S. H. \& Lovibond, P. F. (1995). Manual for the Depression Anxiety Stress Scales (2nd ed.). Sydney: Psychology Foundation.

Lu, X. (2011). Parenting Stress and Psychological Distress among Mothers of Children with Autism in Johor Bahru and Hangzhou. Unpublished Master dissertation, Universiti Tekonologi Malayisa, Johor, Malaysia.

Lu, X., Watanabe, J., Liu, Q. B., Uji, M., Shono, M. \& Kitamura, T. (2011). Internet and Mobile Phone Textmessaging Dependency: Factor Structure and Correlation with Dysphoric mood among Japanese Adults. Computers in Human Behavior, 27, 1702-1709. 
Morrison, C. M. \& Gore, H. (2010). The Relationship between Excessive Internet Use and Depression: A Questionnaire-Based Study of 1319 Young People and Adults. Psychopathology, 43, 121-126. DOI:10.1159/000277001.

Pay-Ling H., Wu, P. L., Chen, S. H. \& Chang, Y. W. (2007). A Study of the Internet Addiction Model for Northern Taiwanese High School Students. Bulletin of Educational Psychology, 38(3), 355-373

Rahmat, H. (2004). Internet Addiction, Locus of Control, and Social Isolation among Malaysian Adolescents. Thesis of Master degree. International Islamic University Malaysia.

Siomos, K. E., Dafouli, E. D., Braimiotis, D. A., Mouzas, O. D., Angelopoulos, N. V. (2008). Internet Addiction among Greek adolescent Students. Cyber Psychology \& Behavior, 11, 653-657.

Thomee, S., Eklo, F. M., Gustafsson, E., Nilsson, R. \& Hagberg, M. (2007). Prevalence of perceived stress, symptoms of depression and sleep disturbances in relation to information and communication technology (ICT) use among young adults: an explorative prospective study. Computers in Human Behavior, 23, 1300-1321.

Whang, L. S., Lee, S. \& Chang, G. (2003).Internet Over-Users' Psychological Profiles: A Behavior Sampling Analysis on Internet Addiction. Cyberpsychology \& Behavior, 6(2), 143-150.

Yang, S. C. \& Tung, C. J. (2007). Comparison of Internet addicts and non-addicts in Taiwanese high school. Computers in Human Behavior, 3, 2379-2396.

Yen, J. Y., Ko, C. H., Yen, C. F., Wu, H. Y. \& Yang, M. J. (2007). The comorbid psychiatric symptoms of Internet addiction: Attention deficit and hyperactivity disorder (ADHD), depression, social phobia, and hostility. Journal of Adolescent Health, 41(1), 93-98.

Young, K. (1998). Internet addiction: The emergence of a new clinical disorder. Cyber Psychology and Behavior, 3, 237-244. 